\title{
BIOFILM FORMATION BY Listeria monocytogenes ON STAINLESS STEEL SURFACE AND BIOTRANSFER POTENTIAL
}

\author{
Maíra Maciel Mattos de Oliveira ${ }^{1}$; Danilo Florisvaldo Brugnera ${ }^{1}$; Eduardo Alves ${ }^{2}$; Roberta Hilsdorf Piccoli $^{1^{*}}$ \\ ${ }^{1}$ Departamento de Ciência dos Alimentos, Universidade Federal de Lavras, Lavras, MG, Brasil; ${ }^{2}$ Departamento de \\ Fitopatologia,Universidade Federal de Lavras, Lavras, MG, Brasil.
}

Submitted: January 24, 2009; Returned to authors for corrections: May 17, 2009; Approved: August 23, 2009.

\begin{abstract}
An experimental model was proposed to study biofilm formation by Listeria monocytogenes ATCC 19117 on AISI 304 (\#4) stainless steel surface and biotransfer potential during this process. In this model, biofilm formation was conducted on the surface of stainless steel coupons, set on a stainless steel base with 4 divisions, each one supporting 21 coupons. Trypic Soy Broth was used as bacterial growth substrate, with incubation at $37{ }^{\circ} \mathrm{C}$ and stirring of $50 \mathrm{rpm}$. The number of adhered cells was determined after 3, 48, 96, 144, 192 and 240 hours of biofilm formation and biotransfer potential from 96 hours. Stainless steel coupons were submitted to Scanning Electron Microscopy (SEM) after 3, 144 and 240 hours. Based on the number of adhered cells and SEM, it was observed that L. monocytogenes adhered rapidly to the stainless steel surface, with mature biofilm being formed after 240 hours. The biotransfer potential of bacterium to substrate occurred at all the stages analyzed. The rapid capacity of adhesion to surface, combined with biotransfer potential throughout the biofilm formation stages, make L. monocytogenes a potential risk to the food industry. Both the experimental model developed and the methodology used were efficient in the study of biofilm formation by L. monocytogenes on stainless steel surface and biotransfer potential.
\end{abstract}

Key words: Listeria monocytogenes, biofilm, biotransfer potential.

\section{INTRODUCTION}

The term biofilm was created to describe the sessile form of microbial life, characterized by adhesion of microorganisms to biotic or abiotic surfaces, with consequent production of extracellular polymeric substances (35). Microbial adhesion and biofilms are of great importance for the food industry and occur on a high variety of food contact surfaces (29). In food processing industries, surfaces of stainless steel equipment and utensils are recognized as the major microbial adhesion and biofilm formation sites (13).

Surface-adhered microbial cells contaminate food products during the processing. This ability of transferring microorganisms through contact with food is termed biotransfer potential. Viable microorganisms adhered to surfaces will present a biotransfer potential even if the number of cells present is low or if it varies within a particular area (23, $30)$.

\footnotetext{
*Corresponding Author. Mailing address: Departamento de Ciência dos Alimentos, Universidade Federal de Lavras, Caixa Postal 3037, CEP 37200-000, Lavras, MG, Brasil.; Tel.: + 55353829 1656 Fax: + 55353829 1401.; E-mail: rhpiccoli@ufla.br
} 
Several microorganisms are capable of participating in the adhesion processes and biofilm formation. In the food industry, these microorganisms can be classified as spoilage and pathogenic. Among the pathogenic microorganisms, $L$. monocytogenes is one of the most outstanding. This bacterium is an emergent pathogen of ubiquitous distribution in nature, surviving under adverse environmental conditions. Developing in different substrates, it is capable of colonizing biotic and abiotic surfaces $(19,39)$. Studies have shown the capacity of $L$. monocytogenes to persist in the environment for years $(28,43)$. Researches on the presence of L. monocytogenes on the surface of equipment and utensils, report its occurrence in meat and dairy processing industries $(11,15,27)$. According to Chae et al. (10), the occurrence of foodborne outbreaks as well as sporadic cases caused by this bacterium, can be attributed to its increased ability of surviving in food processing environments through biofilm formation.

Listeriosis is considered an atypical foodborne disease because of its high severity, non enteric nature and long incubation period (26). Acquired through the ingestion of contaminated food, listeriosis can affect mainly immunocompromised individuals, the elderly, pregnant women and newborns (25). However, there are records of listeriosis outbreaks, characterized by gastrointestinal symptoms accompanied by fever, involving healthy individuals (7, 18, 31). Listeriosis manifests as febrile gastroenteritis (37), meningitis, encephalitis, mother-to-fetus infections and septicemia, resulting in death in $25-30 \%$ of cases (25). Thus, the high risk of food contamination by sessile cells of $L$. monocytogenes, with consequent infection dissemination makes it necessary to develop control strategies aimed to delay, reduce, or even eliminate the accumulation of this bacterium on industrial surfaces. According to Oliveira et al. (36), it has been recognized that a greater understanding of the interaction between microorganisms and food processing surfaces is required to control these problems.

The association of L. monocytogenes to surfaces has been mainly analyzed in the laboratory. However, such studies still need to be standardized, since they are difficult to carry out in situ, in food processing environments (33). The difficulty found in investigating microbial biofilms in nature and the precarious experimental conditions found in most laboratories led to the development of different experimental models of biofilm formation in vitro (38). These systems allow the study of biofilms under defined and controlled conditions and are necessary for the execution of reproducible experiments (22).

This work proposes the use of an experimental model to study biofilm formation by L. monocytogenes ATCC 19117 on AISI 304 (\#4) stainless steel surface and biotransfer potential.

\section{MATERIALS AND METHODS}

\section{Experiment execution sites}

The experiment was carried out at the Federal University of Lavras (Lavras - MG, Brazil), in the Food Microbiology Laboratory of the Department of Food Science and Electron Microscopy and Ultra Structural Analysis Laboratory.

\section{Microorganism used, standardization, inoculum preparation and storage}

The microorganism used was L. monocytogenes ATCC 19117, acquired from the Culture Collection Section of the Medical Biology Division of the Adolfo Lutz Institute (São Paulo - SP, Brazil). To standardize the number of cells, the strain was initially inoculated in an Erlenmeyer flask containing $150 \mathrm{~mL}$ of Trypic Soy Broth (TSB) (Himedia ${ }^{\circledR}$, Mumbai, Maharashtra, India), incubated at $37^{\circ} \mathrm{C}$. The growth curve was determined by performing periodic absorbance readings $(600 \mathrm{~nm})$ and serial dilutions in saline solution $[\mathrm{NaCl}$ $0.9 \%(\mathrm{p} / \mathrm{v})]$. Then, from the saline solution, and using Trypic Soy Agar (TSA) (Himedia ${ }^{\circledR}$, Mumbai, Maharashtra, India) as culture medium, spread plating methodology was improved to determine the Log CFU.mL ${ }^{-1}$. Throughout the experiment, the strain was stored under refrigeration in freezing culture medium (15 mL glycerol, $0.5 \mathrm{~g}$ bacteriological peptone, 0.3 of yeast extract and $0.5 \mathrm{~g} \mathrm{NaCl}$, per $100 \mathrm{~mL}$ of distilled water, with the final $\mathrm{pH}$ adjusted to $7.2 \pm 7.4$ ). For strain reactivation and use, an aliquot of the freezing culture medium was 
transferred to test tubes containing TSB, with two subcultures at $37{ }^{\circ} \mathrm{C}$ for 24 hours. The culture was striated in TSA added to Petri dishes and incubated at $37{ }^{\circ} \mathrm{C}$ for 24 hours. Of the colonies formed on the TSA surface, some were removed and transferred into an Erlenmeyer flask containing $150 \mathrm{~mL}$ of TSB, which was incubated at $37{ }^{\circ} \mathrm{C}$ until reaching the number of cells necessary for the experiment, approximately 9.17 Log CFU.mL $L^{-1}\left(\mathrm{OD}_{600 \mathrm{~nm}}=0.895\right)$.

\section{Biofilm formation experimental model}

The experimental model of biofilm formation by $L$. monocytogenes (Figure 1A) was elaborated based on a system first used by Bagge et al. (3) and Gram et al. (21), with modifications. In the present study, the experimental model consisted of the following items: AISI 304 (\#4) stainless steel base, with 4 divisions, each supporting 21 AISI 304 (\#4) stainless steel coupons ( 1 x 8 x $18 \mathrm{~mm})$, vertically displaced (Figure 1B); $1000 \mathrm{~mL}$ beaker; magnetic bar and magnetic agitator to allow the free circulation of the substrate inside the beaker. The beaker was sealed with a Petri dish and plastic film. AISI 304 (\#4) stainless steel was chosen for being the most utilized in the food industry.
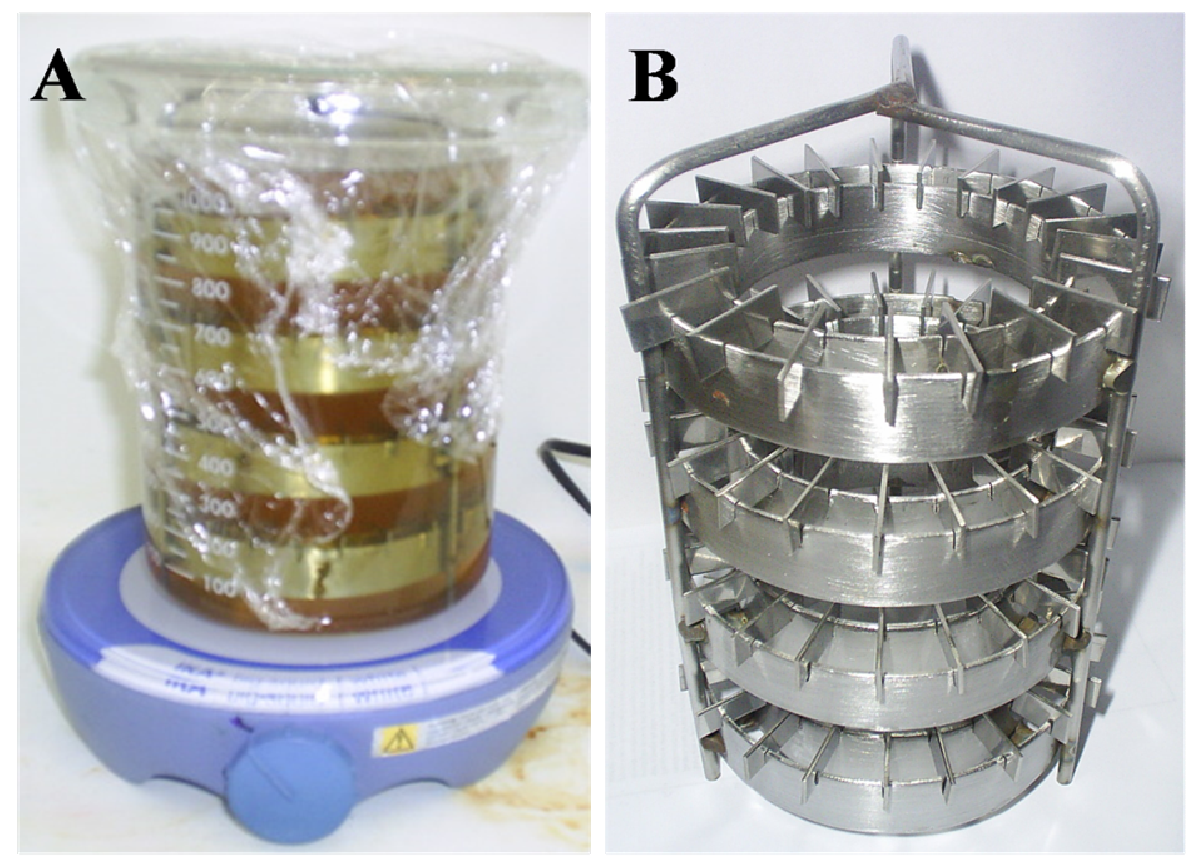

Figure 1. (A) Experimental model of biofilm formation, using the culture medium Trypic Soy Broth (TSB) as substrate. (B) Base and AISI 304 (\#4) stainless steel coupons used in the biofilm formation experimental model.

\section{Preparation of the coupons and stainless steel base}

In order to initiate the bacterial cell adhesion stage, the coupons and stainless steel base were previously hygienized and sterilized. First they were cleaned with acetone $100 \%$, washed by immersion in alkaline detergent $[\mathrm{NaOH} 1 \%(\mathrm{w} / \mathrm{v})$, $\mathrm{pH}$ 13.2] for 1 hour, rinsed with sterilized distilled water, dried and cleaned with alcohol $70 \%(\mathrm{v} / \mathrm{v})$. After the hygienization, they were washed with sterilized distilled water, dried for 2 hours at $60{ }^{\circ} \mathrm{C}$ and autoclaved at $121^{\circ} \mathrm{C}$ for 15 minutes (41).

\section{Bacterial cell adhesion to stainless steel coupon surface}

Initially, $1000 \mathrm{~mL}$ of TSB previously sterilized and $70 \mathrm{~mL}$ of TSB containing the bacterial culture were added to the beaker containing the magnetic bar, at a final concentration of 
approximately 8 Log CFU.mL ${ }^{-1}$.The stainless steel base containing the coupons was placed inside the beaker, which was sealed and incubated at $37{ }^{\circ} \mathrm{C}$ under $50 \mathrm{rpm}$ agitation. Every 48 hours, the coupons were removed from the base and immersed three times into a saline solution to remove the planktonic cells, and again placed in a new sterilized base, which was immersed in $1000 \mathrm{~mL}$ of TSB in a beaker containing a magnetic bar. Both the TSB and the beaker with the magnetic bar had been also previously sterilized. The system was sealed and incubated at $37{ }^{\circ} \mathrm{C}$ under $50 \mathrm{rpm}$ agitation. This procedure was repeated every 48 hours, completing 240 hours of incubation, to form a mature biofilm.

The substitution of the stainless steel base, beaker, magnetic bar and culture medium (TSB) every 48 hours as well as the removal of the planktonic cells aimed to simulate the permanence of the stainless steel surface-adhered cells, after the incorrectly conducted hygienization procedure, in the food industry.

\section{Enumeration of the adhered bacterial cells}

The number of bacterial cells adhered to the stainless steel coupons was determined after 3, 48, 96, 144, 192 and 240 hours of cultivation. Initially, the coupons were immersed three times in saline solution to remove the planktonic cells, followed by the removal of the adhered cells using previously sterilized standardized swabs $(15 \mathrm{~mm}$ x $25 \mathrm{~mm})$. The swabs were transferred to test tubes containing $10 \mathrm{~mL}$ of saline solution and stirred in vortex for one minute. Serial dilutions of up to $10^{-6}$ were made in test tubes containing $9 \mathrm{~mL}$ of saline solution. Aliquots of $100 \mu \mathrm{L}$ of each dilution were inoculated in Petri dishes containing TSA, using the spread plate technique. Afterwards, the Petri dishes were incubated at $37^{\circ} \mathrm{C}$ for 24 hours. For each measuring period, two randomly collected coupons were used as replicates. Three repetitions of the experiments were conducted, and in each, results were expressed by the coupons average in Log CFU.cm ${ }^{-2}$.

\section{Scanning Electron Microscopy (SEM)}

Stainless steel coupons were submitted to SEM after 3, 144 and 240 hours of biofilm formation The coupons were initially immersed in a fixing solution (modified Karnovsky's: glutharaldehyde $2.5 \%$, formaldehyde $2.5 \%$ in sodium cacodylate buffer $0.05 \mathrm{M}, \mathrm{pH} 7.2, \mathrm{CaCl}_{2} 0.001 \mathrm{M}$ ) for a minimum of 24 hours, washed with sodium cacodylate buffer three times for 10 minutes, fixed in osmium tetroxide $(1 \%$ in distilled water) for 1 hour at ambient temperature in an exhaust hood, washed three times in distilled water and dehydrated in acetone gradient $(25 \%, 50 \%, 75 \%, 90 \%$ and 100\%, three times). The coupons were later transferred to the critical point apparatus (Bal-tec CPD 030) to complete drying, mounted on stubs and sputter-coated with gold (Bal-tec CPD 050) (5). At the end of this procedure, the coupons were examined in a scanning electron microscope (EVO 040 Leo) to obtain the micrographs.

\section{Biotransfer potential evaluation}

With the aim of determining the number of planktonic cells present, aliquots of $1 \mathrm{~mL}$ of TSB were removed from the beaker at $0,3,48,96,144,192$ and 240 hours of stainless steel coupons incubation. After 48 hours, these aliquots were immediately removed before the exchange of the culture medium (TSB). Serial dilutions up to $10^{-10}$ were carried out in test tubes containing $9 \mathrm{~mL}$ of saline solution. Aliquots of 100 $\mu \mathrm{L}$ of each dilution were inoculated in Petri dishes containing TSA, using the spread plate technique. The Petri dishes were incubated at $37{ }^{\circ} \mathrm{C}$ for 24 hours. The evaluation of the biofilm cell detachment to the culture medium was conducted by the values obtained at 96, 144, 192 and 240 hours, considering that up to 48 hours the number of planktonic cells referred to the initial inoculum, since the culture medium was not yet replaced by another sterile. Thus, the ability to detach and contaminate the sterile substrate, showed by sessile cells, was considered as biotransfer potential, which was demonstrated by the presence of planktonic cells in the substrate after contact with contaminated surfaces. The experiment was repeated three times and the result was expressed in Log CFU.mL ${ }^{-1}$.

\section{Determination of the initial adhesion capacity}

Initial adhesion capacity was determined in each repetition

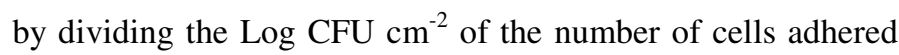


after 3 hours by the number of cells of the initial inoculum in Log CFU.mL ${ }^{-1}$. The result was multiplied by $100(8,10)$.

\section{RESULTS AND DISCUSSION}

L. monocytogenes adhered to the stainless steel surface, presented a count of 4.89 Log CFU. $\mathrm{cm}^{-2}$ after 3 hours of contact (Table 1). As observed by the plate count method, via
SEM, a rapid adherence of $L$. monocytogenes to the surface was also verified. After 3 hours of contact, the distribution of the surface-adhered cells occurred irregularly. At this stage, two different situations were observed. In some areas, several cells were adhered to the surface. Most were in the process of binary fission, indicating possible posterior formation of microcolonies (Figure 2A). However, in some places, the bacterial adherence observed was not so evident (Figure 2B).

Table 1. Number of planktonic (Log CFU.mL ${ }^{-1}$ ) and sessile (Log CFU.cm ${ }^{-2}$ ) cells of Listeria monocytogenes, quantified during biofilm formation on AISI 304 (\#4) stainless steel surface, with incubation at $37{ }^{\circ} \mathrm{C}$ and using the culture medium Trypic Soy Broth (TSB) as substrate.

\begin{tabular}{ccc}
\hline $\begin{array}{c}\text { Time } \\
\text { (hours) }\end{array}$ & $\begin{array}{c}\text { TSB } \\
(\text { Log CFU.mL }\end{array}$ & $\begin{array}{c}\text { Stainless steel } \\
\left(\text { Log CFU.cm }^{-2}\right)\end{array}$ \\
\hline 3 & $8.97 \pm 0.16$ & $4.89 \pm 0.03$ \\
48 & $8.85 \pm 0.65$ & $4.08 \pm 0.67$ \\
96 & $9.95 \pm 0.62$ & $4.64 \pm 0.57$ \\
144 & $9.55 \pm 0.17$ & $4.63 \pm 0.60$ \\
192 & $9.74 \pm 0.11$ & $4.52 \pm 0.47$ \\
240 & $9.36 \pm 0.03$ & $5.64 \pm 1.07$ \\
\hline
\end{tabular}

Results referring to the average of three repetitions \pm the standard deviation.

Bacterial adhesion capacity occurs as a function of the initial inoculum (time 0 ) and it is a parameter that evaluates the ability of free cells, originating from a liquid medium, to adhere to solid surfaces, which corresponds to the first stage of biofilm development. Initial adhesion capacity, measured during 3 hours, was $58.75 \pm 0.90 \%$ and corresponded to an inoculum of $8.26 \pm 0.18$ Log CFU.mL ${ }^{-1}\left(\mathrm{OD}_{600 \mathrm{~nm}}=0.873 \pm\right.$ 0.04).

The adhesion of bacteria to surfaces occurs in two stages: reversible followed by irreversible adhesion (32). During reversible adhesion, bacteria are easily removed by applying minimum force (13). Irreversible adhesion initiates after 20 minutes to a maximum of 4 hours of contact at $4-20^{\circ} \mathrm{C}(23,45)$ and presents serious risks to the food industry, since the removal of irreversibly adhered cells is difficult and requires the application of strong mechanical force or chemical interruption of the adhesion using surfactants, sanifiers or heat (44). Thus, there is a high probability that the irreversibly adhered cells will remain even after hygienization. This is one of the main reasons for biofilm formation on surfaces in contact with food. This risk is aggravated with respect to $L$. monoctogenes, since this study observed that this bacterium has the capacity of rapidly adhering to stainless steel, being able to reach an irreversible stage in a few hours.

Even with the addition of a new culture medium, without inoculum after 48 hours up to 192 hours, the number of surface-adhered bacterial cells remained practically constant (Table 1). During this period, only bacterial adhesion was observed, i.e., there was no mature biofilm formation. It was observed through SEM that after 144 hours of contact, the distribution of the L. monocytogenes cells adhered to the surface was uniform. However, in some places cellular density 
was found to be still lower (Figure 2C) than in others (Figure 2D). At this stage, no presence or formation of microcolonies were observed, contrary to the earlier stage ( 3 hours). This can be explained by the possible variability between the stainless steel coupons regarding bacterial adherence. It was also observed at this stage (144 hours) that, although the number of surface adhered cells was similar to that found after 3 hours of biofilm formation (Table 1), the result obtained by SEM (Figures 2C and 2D) differed completely from that found at 3 hours (Figures 2A and 2B). Thus, it can be concluded that even with the similarity between the number of cells adhered after 3 and 144 hours (Table 1), cell display on the surface may be changed with longer contact time between the cells and the adhesion surface, making it more uniform.

Similar results were observed by Kalmokoff et al. (24), who studied biofilm formation by different strains of $L$. monocytogenes on stainless steel surface. After 72 hours of contact at $21{ }^{\circ} \mathrm{C}$ using the Brain Heart Infusion broth as substrate, the authors observed under SEM that most of the strains did not form biofilm under these conditions, but rather adhered uniformly to the surface. Despite the differences in the density of the adhered cells among the strains, few cellular groupings were observed.

It was possible to observe a large difference between the size of L. monocytogenes sessile cells in Figures 2A and 2C, since both the scanning electron micrographs showed the same magnification. This fact can be explained by the difference in size that L. monocytogenes cells can have, especially with regard to length. According to Adams and Moss (1), L. monocytogenes is a Gram-positive rod, with 0.4 to $0.5 \mu \mathrm{m}$ in diameter and 0.5 to $2.0 \mu \mathrm{m}$ in length. The difference in size between bacteria belonging to this species occurs, mainly due to their stage of development.

After 240 hours, an increase in the number of adhered cells was observed, with a count of 5.64 Log CFU.cm ${ }^{-2}$ (Table 1). The differentiation between adhesion and biofilm formation has been proposed as a function of the amount of cells present per $\mathrm{cm}^{2}$. One of the most currently cited values is that proposed by Andrade et al. (2), who studied adhesion of Enterococcus faecium to stainless steel surface and emphasized that in order for biofilm formation to occur counts above 7 Log CFU.cm ${ }^{-2}$ are necessary. However, to differentiate adhesion from biofilm, the bacterial species involved must be observed, since it is known that distinct species will present different adhesion behaviors and biofilm formation. Thus, this study considered only the propositions specifically made for L. monocytogenes regarding the number of adhered cells necessary for mature biofilm formation, and not only bacterial adhesion.

L. monocytogenes has the capacity to adhere rapidly to stainless steel surfaces $(6,40)$. However, it is not capable of forming thick biofilms made up of several layers (9 to $12 \mathrm{Log}$ CFU. $\mathrm{cm}^{-2}$ ), but rather of adhering to surfaces at levels ranging from 4 to 6 Log CFU.cm ${ }^{-2}$ (21), which is in agreement with the values obtained in this study. Ronner and Wong (40), studying the development of biofilms by L. monocytogenes on stainless steel surface, obtained counts above 5 Log CFU.cm ${ }^{-2}$, such as that found after 240 hours of cultivation in this experiment, indicating biofilm formation and not only bacterial adhesion.

Chae and Schraft (9) promoted biofilm formation by $L$. monocytogenes Murray and 7148 on the surface of glass coupons for 240 hours of incubation at $37{ }^{\circ} \mathrm{C}$ using TSB as substrate. Counts of approximately 6 Log CFU.cm ${ }^{-2}$ were observed for L. monocytogenes Murray and 5 Log CFU.cm ${ }^{-2}$ for L. monocytogenes 7148 . These data are compatible with those found in this work for stainless steel.

As observed after 3 hours, two different situations were verified by applying SEM after 240 hours concerning the distribution of surface-adhered cells. In the first situation, the formation of small microcolonies was observed, with the presence of extracellular polymeric substances (Figure 2E). Such observation, together with the count of bacterial cells adhered to the surface at 240 hours (5.64 Log CFU.cm ${ }^{-2}$ ), emphasizes the formation of mature biofilm at this stage rather than just bacterial adhesion. However, it must be pointed out that the biofilm formed does not totally cover the surface. In contrast, in some places, the cells were uniformly distributed on the surface (Figure 2F) as observed after 144 hours (Figures 2C and 2D), showing that biofilm maturation and development 
does not occur identically on the entire surface.

In this study, the production of extracellular polymers by L. monocytogenes was found to occur after 240 hours of biofilm formation. The production of extracellular polymers by this species is little studied (10). Borucki et al. (4), observed the formation of exopolysaccharides by different strains of $L$. monocytogenes. According to the authors, the strains with a greater biofilm formation capacity were those producing the most exopolysaccharides, indicating that the production of extracellular polymers, such as that observed at 240 hours in this study (arrows in the Figure 2E), is a key factor for $L$. monocytogenes biofilm maturation.
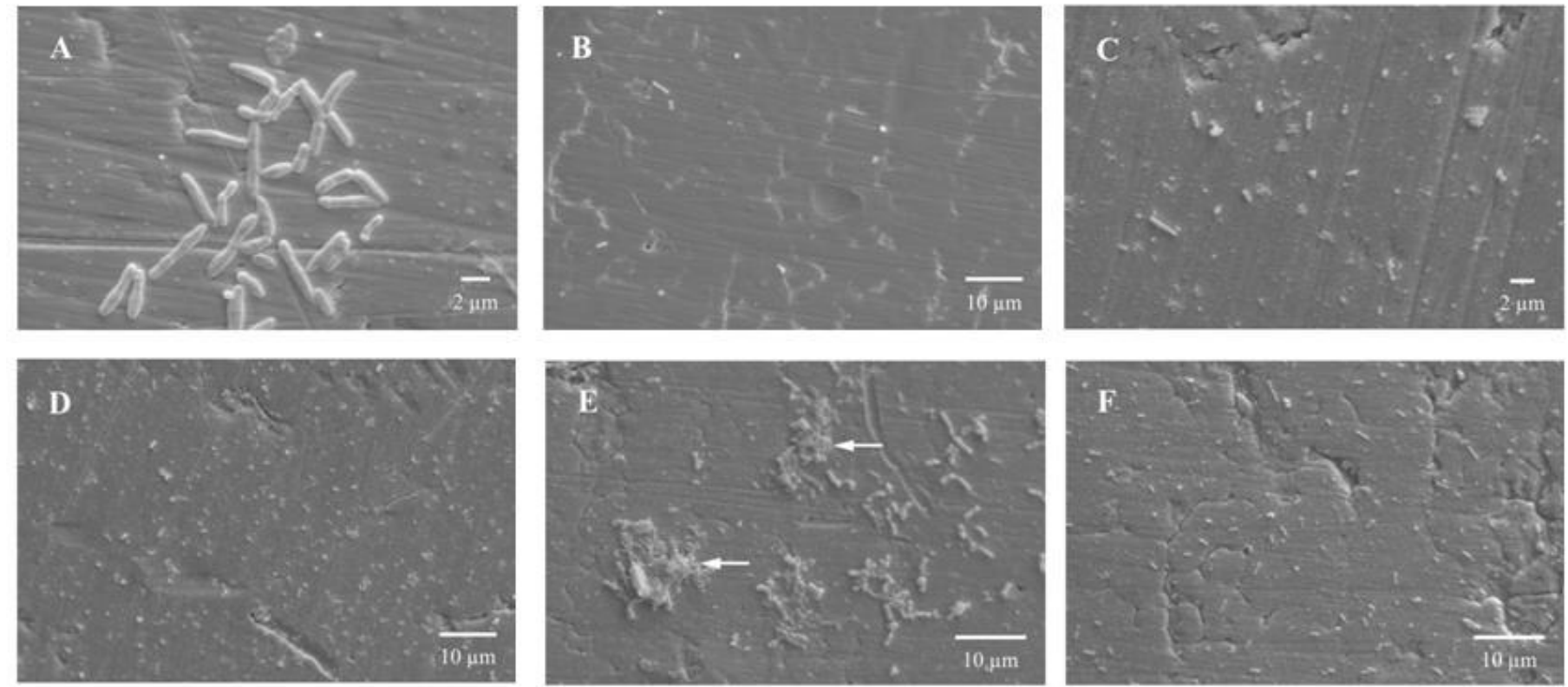

Figure 2. Scanning electron micrographs showing the adherence of Listeria monocytogenes on AISI 304 (\#4) stainless steel surface, after 3 (A and B), 144 (C and D) and 240 hours (E and F) of contact at $37{ }^{\circ} \mathrm{C}$, using Trypic Soy Broth (TSB) culture medium as substrate. (A) Surface-adhered cells, most of which in process of binary fission. (B) Visualization of a larger coupon area showing little cell adherence. (C) Lower cellular density. (D) Higher cellular density. (E) Mature biofilm with the presence of extracellular polymeric substances, as indicated by the arrows. (F) Uniformly-adhered cells.

Mature biofilm formation occurs from 72 to 144 hours after initial adhesion, and may reach 240 hours (22). Maturity occurs mainly through population density increase as well as by pronounced production and deposition of extracellular polymers, increasing biofilm thickness (12). These extracellular polymers are produced by the cells established within the biofilm structure (48) and are composed of several substances, including polysaccharides, proteins and nucleic acids $(34,47)$. The matrix of extracellular polymeric substances is responsible for the morphology, structure, cohesion and functional integrity of the biofilm. Its heterogeneous and complex chemical composition determines most of the physical-chemical and biological properties (16). In the food industry, it confers resistance to the commonly applied hygienization procedures (20), making it difficult for the mature biofilms to be completely removed from these surfaces.

One of the great biofilm formation issues in the food industry or other areas is cell detachment, which makes it a constant source of microorganism contamination in food, water, or new infection processes. Thus, the evaluation of the 
biotransfer potential of microorganisms is interesting. This can be observed from the values found after 96 hours of biofilm formation. The planktonic cell count found (Table 1) indicates that the detachment of $L$. monocytogenes cells from the stainless steel surface was practically constant during the stages analyzed (96, 144, 192 and 240 hours). This shows that such capacity is independent from total biofilm maturation, contradicting previous reports by several authors $(13,14,42$, 46). The high values found in all the stages analyzed ( $>9 \log$ CFU.mL ${ }^{-1}$ ) can be attributed to the existence of adequate growth conditions, such as temperature and necessary nutrients. To these factors is added the planktonic condition of the cell, which is completely immersed in the culture medium, rapidly metabolizing the nutrients dispersed in the substrate, making it easier to obtain energy and allowing cell division to occur quickly.

Few studies about the biotransfer potential have been made. Flint et al. (17), observed the detachment of Bacillus stearothermophilus cells, present on stainless steel surface, into milk passing over the biofilm. Nevertheless, there were no studies evaluating L. monocytogenes biotransfer potential.

Rapid surface adhesion capacity, combined with biotransfer potential throughout the stages of biofilm formation, make L. monocytogenes a potential risk to the food industry. Once present in the raw material, L. monocytogenes will adhere rapidly to the surface of stainless steel equipment and utensils, being able to multiply, forming mature biofilms quickly. Biotransfer potential combined with survival and multiplication capacity in different substrates will cause this bacterium to rapidly reach infecting doses.

Based on the results obtained, we can infer that the experimental model developed and the methodology applied were efficient in studying biofilm formation by $L$. monocytogenes on stainless steel surface, as well to evaluate the biotransfer potential. However, we can observe that the study of bacterial biofilm formation, besides applying plate count of the number of the surface-adhered cells, must include microscopy methods that allow observation of not only bacterial population increases but also of fundamental aspects, such as the arrangement of cells on the surface and the presence of extracellular polymeric substances responsible for the cohesion and protection of the cells present in the biofilm structure.

Despite previous studies $(3,21)$ who also demonstrated successfully bacterial biofilm development using experimental models similar to that one adopted in this research, this work emphasizes the use of the experimental model developed as a new tool to assess the biotransfer potential, which had not yet been demonstrated.

Thus, it was concluded that this is a useful technique to be employed in future studies based on the evaluation of biotransfer potential to different substrates, bacterial adherence and biofilm formation on stainless steel surface, as well as in studies aimed at developing methods to remove the adhered cells.

\section{ACKNOWLEDGEMENTS}

The authors thank the National Counsel of Technological and Scientific Development (CNPq) for the first author's scholarship, and the Research Support Foundation of the State of Minas Gerais (FAPEMIG) for the financial support.

\section{REFERENCES}

1. Adams, M.R.; Moss, M.O. (2004). Food microbiology. The Royal Society of Chemistry, Cambridge, England.

2. Andrade, N.J.; Bridgeman, T.A.; Zottola, E.A. (1998). Bacteriocidal activity of sanitizers against Enterococcus faecium attached to stainless steel as determined by plate count and impedance methods. J. Food Prot. 61 (7), 833-838.

3. Bagge, D.; Hjelm, M.; Johansen, C.; Huber, I.; Gram, L. (2001). Shewanella putrefaciens adhesion and biofilm formation on food processing surfaces. Appl. Environ. Microbiol. 67 (5), 2319-2325.

4. Borucki, M.K.; Peppin, J.D.; White, D.; Loge, F.; Call, D.R. (2003). Variation in biofilm formation among strains of Listeria monocytogenes. Appl. Environ. Microbiol. 69 (12), 7336-7342.

5. Bossola, J.J.; Russell, L.D. (1998). Electron microscopy. Jones and Bartlett, Boston, 670p.

6. Briandet, R.; Leriche, V.; Carpentier, B.; Bellon-Fontaine, M.N. (1999). Effects of the growth procedure on the surface hydrophobicity of Listeria 
monocytogenes cells and their adhesion to stainless steel. J. Food Prot. $62(9), 994-998$.

7. Carrique-Mas, J.J.; Hokeberg, I.; Andersson Y.; Arneborn, M.; Tham, W.; Danielsson-Tham, M.L.; Osterman, B.; Leffler, M.; Steen, M.; Eriksson, E.; Hedin, G.; Giesecke, J. (2003). Febrile gastroenteritis after eating on-farm manufactured fresh cheese-an outbreak of listeriosis? Epidemiol. Infect. 130 (1), 79-86.

8. Chae, M.S.; Schraft, H. (2000). Comparative evaluation of adhesion and biofilm formation of different Listeria monocytogenes strains. Int. J. Food Microbiol. 62 (1), 103-111.

9. Chae, M.S.; Schraft, H. (2001). Cell viability of Listeria monocytogenes biofilms. Food Microbiol. 18 (1), 103-112.

10. Chae, M.S.; Schraft, H.; Hansen, L.T.; Mackereth, R. (2006). Effects of physicochemical surface characteristics of Listeria monocytogenes strains on attachment to glass. Food Microbiol. 23 (3), 250-259.

11. Chambel, L.; Sol, M.; Fernandes, I.; Barbosa, M.; Zilhão, I.; Barata, B.; Jordan, S.; Perni, S.; Shama, G.; Adrião, A.; Faleiro, L.; Requena, T.; Peláez, C.; Andrew, P.W.; Tenreiro, R. (2007). Occurrence and persistence of Listeria spp. in the environment of ewe and cow's milk cheese dairies in Portugal unveiled by an integrated analysis of identification, typing and spatial-temporal mapping along production cycle. Int. J. Food Microbiol. 116 (1), 52-63.

12. Cheng, C.; Zhang, Z.; Chen, S.; Bryersand, J.D.; Jiang, S. (2007). Inhibition of bacterial adhesion and biofilm formation on zwitterionic surfaces. Biomaterials. 28 (29), 4192-4199.

13. Chmielewski, R.A.N.; Frank, J.F. (2003). Biofilm formation and control in food processing facilities. Int. J. Food Sci. Tech. 2 (1), 22-32.

14. Christensen, B.E.; Characklis, W.G. (1990). Physical and chemical properties of biofilms. In: Characklis, W. G.; Marshall, K. C. (eds). Biofilms. John Wiley and Sons, Inc, New York, p.93-130.

15. Cruz, C.D.; Silvestre, F.A.; Kinoshita, E.M.; Landgraf, M.; Franco, B.D.G.M.; Destro, M.T. (2008). Epidemiological survey of Listeria monocytogenes in a gravlax salmon processing line. Braz. J. Microbiol. 39 (2), 375-383.

16. Flemming, H.C.; Windenger, J. (1999). Extracellular polymeric substances (EPS): the biofilm construction material. In: Weber, J.; Sand, W. (eds). Biofouling and Materials: EDMZ, COST 520 Workshop, p.218.

17. Flint, S.; Palmer, J.; Bloemen, K.; Brooks, J.; Crawford, R. (2001). The growth of Bacillus stearothermophilus on stainless steel. J. Appl. Microbiol. 90 (2), 151-157.

18. Frye, D.M.; Zweig, R.; Sturgeon, J.; Tormey, M.; LeCavalier, M.; Lee, I.; Lawani, L.; Mascola, L. (2003). An outbreak of febrile gastroenteritis associated with delicatessen meat contaminated with Listeria monocytogenes. Clin. Infect. Dis. 35 (8), 943-9.

19. Gandhi, M.; Chikindas, M.L. (2007). Listeria: a foodborne pathogen that knows how to survive. Int. J. Food Microbiol. 113 (1), 1-15.
20. Gilbert, P.; Mcbain, A.J. (2003). Potential Impact of Increased Use of Biocides in Consumer Products on Prevalence of Antibiotic Resistence. Clin. Microbiol. Rev. 16 (2), 189-208.

21. Gram, L.; Bagge-Ravn, D.; Ng, Y.Y.; Gymoese, P.; Vogel, B.F. (2007). Influence of food soiling matrix on cleaning and disinfection efficiency on surface attached Listeria monocytogenes. Food Control. 18 (10), 1165-1171.

22. Heydorn, A.; Ersbøll, B.K.; Hentzer, M.; Parsek, M.R.; Givskov, M.; Molin, S. (2000). Experimental reproducibility in flow-chamber biofilms. Microbiology. 146 (10), 2409-2415.

23. Hood, S.K.; Zottola, E.A. (1995). Biofilms in food processing. Food Control. 6 (1), 9-18.

24. Kalmokoff, M.L.; Austin, J.W.; Wan, X.-D.; Sanders, G.; Banerjee, S.; Farber, J.M. (2001). Adsorption, attachment and biofilm formation among isolates of Listeria monocytogenes using model conditions. J. Appl. Microbiol. 91(4), 725-734.

25. Khelef, N.; Lecuit, M.; Buchrieser, C.; Cabanes, D.; Dussurget, O.; Cossart, P. (2006). Listeria monocytogenes and the genus Listeria. In: Dworkin, M.; Falkow, S.; Rosenberg, E.; Schleifer, K.H.; Stackebrandt, E.(eds). The prokaryotes: an evolving electronic resource for the microbiological community. Springer, New York, USA, p.404-476.

26. Loguercio, A.P.; Silva, W.P.; Aleixo, J.A.G.; Costa, M.M.; Vargas, A.C. (2001). Listeria monocytogenes: um importante patógeno de origem alimentar. Hig. Aliment. 15 (80/81), 39-48.

27. López, V.; Villatoro, D.; Ortiz, S.; López, P.; Navas, J.; Dávila, J.C.; Martínez-Suárez, J.V. (2008). Molecular tracking of Listeria monocytogenes in an Iberian pig abattoir and processing plant. Meat Sci. $78(1 / 2), 130-134$.

28. Lunden, J.M.; Autio, T.J.; Korkeala, H.J. (2002). Transfer of persistent Listeria monocytogenes contamination between food-processing plants associated with a dicing machine. J. Food Prot. 65 (7), 1129-1133.

29. Marques, S.C.; Rezende, J.G.O.S.; Alves, L.A.F.; Silva, B.C.; Alves, E.; Abreu, L.R.; Piccoli, R.H. (2007). Formation of biofilms by Staphylococcus aureus on stainless steel and glass surfaces and its resistance to some selected chemical sanitizers. Braz. J. Microbiol. 38 (3), 538-543.

30. Midelet, G.; Carpentier, B. (2004). Impact of cleaning and disinfection agents on biofilm structure and on microbial transfer to a solid model food. J. Appl. Microbiol. 97 (2), 262-270.

31. Miettinen, M.K.; Siitonen, A.; Heiskanen, P.; Haajanen, H.; Björkroth, K.J.; Korkeala, H.J. (1999). Molecular epidemiology of an outbreak of febrile gastroenteritis caused by Listeria monocytogenes in cold-smoked rainbow trout. J. Clin. Microbiol. 37 (7), 2358-2360.

32. Mittelman, M.W. (1998). Structure and functional characteristics of bacterial biofilms in fluid processing operations. J. Dairy Sci. 81 (10), 2760-2764. 
Oliveira, M.M.M. et al.

33. Møretrø, T.; Langsrud, S. (2004). Listeria monocytogenes: biofilm formation and persistence in food-processing environments. Biofilms. 1 (2), 107-121.

34. Nielsen, P.H.; Frølund, B.; Keiding, K. (1996). Changes in the composition of extracellular polymeric substances in activated sludge during anaerobic storage. App. Microbiol. Biotechnol. 44 (6), 823-830.

35. Nikolaev, Y.A.; Plakunov, V.K. (2007). Biofilm -"City of Microbes” or an Analogue of Multicellular Organisms? Microbiology. 76 (2), 125-138.

36. Oliveira, K.; Oliveira, T.; Teixeira, P.; Azeredo, J.; Oliveira, R. (2007). Adhesion of Salmonella Enteritidis to stainless steel surfaces. Braz. J. Microbiol. 38 (2), 318-323.

37. Ooi, S.T.; Lorber, B. (2005). Gastroenteritis due to Listeria monocytogenes. Clin. Infect. Dis. 40 (9), 1327-1332.

38. Palmer Jr, R.J. (1999). Microscopy flowcells: perfusion chambers for real-time study of biofilms. Meth. Enzymol. 310, 160-166.

39. Pan, Y.; Breidt Jr., F.; Kathariou, S. (2006). Resistance of Listeria monocytogenes biofilms to sanitizing agents in a simulated food processing environment. Appl. Environ. Microbiol. 72 (12), 7711-7717.

40. Ronner, A.B.; Wong, A.C.L. (1993). Biofilm development and sanitizer inactivation of Listeria monocytogenes and Salmonella typhimurium on stainless-steel and buna-N rubber. J. Food Prot. 56 (9), 750- 758.

41. Rossoni, E.M.M.; Gaylarde, C.C. (2000). Comparison of sodium hypoclorite and peracetic acid as sanitizing agents for stainless steel food processing surfaces using epifluorescence microscopy. Int. J. Food
Microbiol. 61 (1), 81-85.

42. Sauer, K.; Camper, A.K.; Ehrlich, G.D.; Costerton, J.W.; Davies, D.G. (2002). Pseudomonas aeruginosa displays multiple phenotypes during development as a biofilm. J. Bact. 184 (4), 1140-1154.

43. Senczek, D.; Stephan, R.; Untermann, F. (2000). Pulsed-field gel electrophoresis (PFGE) typing of Listeria strains isolated from a meat processing plant over a 2-year period. Int. J. Food Microbiol. 62 (1/2), 155-159, 2000.

44. Sinde, E.; Carballo, J. (2000). Attachment of Salmonella spp. and Listeria monocytogenes to stainless steel, rubber and polytetrafluorethylene: the influence of free energy and the effect of commercial sanitizers. Food Microbiol. 17 (4), 439-447.

45. Smoot, L.M.; Pierson, M.D. (1998). Effect of environmental stress on the ability of Listeria monocytogenes Scott A to attach to food contact surfaces. J. Food Prot. 61 (10), 1293-1298.

46. Trachoo, N. (2003). Biofilms and the food industry. Songklanakarin J. Sci. Technol. 25 (6), 807-815.

47. Tsuneda, S.; Aikawa, H.; Hayashi, H.; Yuasa, A.; Hirata, A. (2003). Extracellular polymeric substances responsible for bacterial adhesion onto solid surface. FEMS Microbiol. Lett. 223 (2), 287-292.

48. Zhang, X.Q.; Bishop, P.L.; Kupferle, M.J. (1998). Measurement of polysaccharides and proteins in biofilm extracellular polymers. Water Sci. Technol. 37 (4/5), 345-348. 